\title{
Statistical Thermal Stability of PVC
}

\author{
Sevdiye Atakul Savrık, Beyhan Cansever Erdoğan, Devrim Balköse, Semra Ülkü \\ Chemical Engineering Department, Faculty of Engineering, Izmir Institute of Technology, Gulbahce Koyu, Urla, \\ Izmir 35430, Turkey
}

Received 9 March 2009; Revised 19 October 2009; accepted 31 October 2009

DOI 10.1002/app.31763

Published online 5 January 2010 in Wiley InterScience (www.interscience.wiley.com).

\begin{abstract}
Experimental design was used to optimize the processing parameters for the decomposition of poly (vinyl chloride). Factorial design and face centered composite design (FCC) were applied to determine the optimum conditions. A total of $10 \mathrm{~g}$ PVC powder was mixed with different amounts of zinc stearate $\left(\mathrm{ZnSt}_{2}\right)$ and natural zeolite and tested for thermal stability. Factorial fitted model was explained by first order pattern due to the significant main effect regression constants, and FCC model was described by second order model owing to higher order polynomial coefficients. FCC design was superior to factorial design as FCC considers not only its pure quad-
\end{abstract}

ratic effects contribution but also its higher overall desirability for thermal stability of PVC. For factorial design the optimum conditions were determined as $163.06 \mathrm{mg}$ for $\mathrm{ZnSt}_{2}, 399.99 \mathrm{mg}$ for zeolite, and $140^{\circ} \mathrm{C}$ for temperature with desirability of 0.933 . However, $400 \mathrm{mg}$ for $\mathrm{ZnSt}_{2}$, $333.24 \mathrm{mg}$ for zeolite, and $140^{\circ} \mathrm{C}$ for temperature with desirability of 0.956 were obtained as the optimum conditions by FCC design. (C) 2010 Wiley Periodicals, Inc. J Appl Polym Sci 116: 1811-1822, 2010

Key words: poly(vinyl chloride) (PVC); zeolite; degradation; kinetics; stabilization

\section{INTRODUCTION}

Poly(vinyl chloride) (PVC) is one of the most versatile polymers because it can accept a wide range of additives, which make PVC, among other properties, durable and difficult to break down. It can be applied to different fields from construction (e.g., in pipes and window frames) to packing (foods, plasma, and blood bags). ${ }^{1,2}$ PVC is rarely used alone and is mixed with various additives such as plasticizers and stabilizers. ${ }^{3}$ One of the most serious problems for PVC processing and handling is the rather low thermal stability.

The thermal degradation of PVC has two step processes. The first step mainly involves progressive unzipping of neighboring labile chlorine atoms along the polymer chain by heat, while PVC undergoes a partial carbonization with the release of benzene and other aromatics. ${ }^{4}$ The dehydrochlorination of PVC starts at about $100^{\circ} \mathrm{C}$ and is the reason for discoloration, owing to the formation of poly-ene sequences. It is catalyzed by $\mathrm{HCl}$ evolved (autocatalysis) and also be promoted by other strong acids. To prevent undesirable degradation processes, a number of chemicals can be used as stabilizers, such as lead compounds, organotin compounds, compounds of other metals, and inorganic stabilizers (zeolite and hydrotalcite). Even though thermal stabilizers based on tin and tr).

Correspondence to: S. A. Savrik (sevdiyeatakul@iyte.edu.

Journal of Applied Polymer Science, Vol. 116, 1811-1822 (2010)

(c) 2010 Wiley Periodicals, Inc. cadmium were of the practical interest as stabilizers for PVC, cadmium use in PVC was restricted as this metal was toxic, environmentally hazardous, and had negative health effect, such as lung cancer. Moreover, organotin stabilizers that are derived from tetravalent tin has unpleasant odor during processing and in the finished product of PVC. Besides that, semi volatile compounds can migrate into environment over time from the PVC materials stabilized with organotin compounds. ${ }^{5}$ To overcome the disadvantages of tinand cadmium-based thermal stabilizers, these compounds are substituted by calcium and zinc stabilizers that are nontoxic. Zinc-based stabilizer, which has stronger Lewis acidity, is able to scavenge $\mathrm{HCl}$ and react with labile chlorine atoms of PVC; therefore, it is used as a primary stabilizer in PVC degradation processes. When zinc and calcium stearate stabilizers were compared in the stabilization of PVC, it was observed that the traces in the induction time of the samples stabilized with zinc stearate were more stable than the one stabilized with calcium stearate stabilizer, indicating the power of zinc soap to inhibit the dehydrochlorination of PVC. ${ }^{6,7}$ The main role of zinc stearate in the degradation of PVC is the substitution of allylic chlorine in PVC with carboxylate group of the zinc soap as indicated in eq. (1), and this stabilizer makes PVC more resistant to heat.

$$
\left(\mathrm{RCOO}^{-}\right)_{2} \mathrm{Zn}_{(\mathrm{s})}+2 \mathrm{R}_{1}-\mathrm{Cl} \rightarrow 2 \mathrm{RCOOR}_{1}+\mathrm{ZnCl}_{2(\mathrm{~s})}
$$

where $R_{1}$ represents the PVC polymer chain except an allylic chlorine. However, the formed $\mathrm{ZnCl}_{2}$ in 
eq. (1) is a Lewis acid, and it will also accelerate dehydrochlorination after its concentration reaches a certain level. ${ }^{8,9}$ Therefore, it is essential to use a secondary stabilizer in PVC to capture evolved $\mathrm{HCl}$ and neutralize other strong acids which catalyze the dehydrochlorination of PVC. ${ }^{4,10}$ In literature, inorganic stabilizers such as hydrotalcite, clay, and zeolite are promising materials as they have tendency to neutralize the acidic medium.

The effect hydrotalcite on the thermal stability of PVC was investigated as the interlayer counterions of this anion-exchanging clay initially react with $\mathrm{HCl}$, and second, the layers react with $\mathrm{HCl}$ to form metal chlorides with loss of the layered structure. ${ }^{11,12}$ It can be seen that the thermal stability time of PVC-hydrotalcite composite resins is greater than that of pure PVC resin and increases as the weight fraction of the hydrotalcite increases. ${ }^{12}$ A natural zeolite, clinoptilolite tends to neutralize the aqueous medium acting either as proton acceptor or as a proton donor due to its amphoteric character. ${ }^{13}$ Brønsted and Lewis acidic/basic sites existing in the microporous structure of the zeolitic materials are responsible for their chemical behavior in aqueous solutions. The neutralization of the aqueous medium can be result of the removal of protons from surface Brønsted acidic sites or the binding of protons to the Lewis basic sites of the zeolite. ${ }^{14}$ Zeolite addition in PVC not only enhances the thermal stabilization of PVC but also it effects the mechanical properties of PVC. Young modulus of PVC-zeolite foams increases with increasing the concentration of zeolite in PVC foam. The addition of $20 \%$ (by weight) zeolite increases Young Modulus value from 1.53 to $8.67 \mathrm{~N} / \mathrm{mm}^{2} .15$

In the previous study, the stabilizing effect of natural zeolite (clinoptilolite) on the stabilization of PVC plastigel at 140 and $160^{\circ} \mathrm{C}$ was confirmed. ${ }^{8}$ Thermal stability of PVC can be determined by PVC Thermomat instrument in which induction and stability time, initial and linear region rate constant of dehydrochlorination reaction can be measured. ${ }^{8}$ When PVC is heated in PVC Thermomat, $\mathrm{HCl}$ evolved is carried by flowing nitrogen gas through a fixed amount of water. The conductivity of water increases with respect to time as $\mathrm{HCl}$ dissolved in it. The period when the conductivity starts to increase is called induction time. It is indicated by the maximum of the second derivative of conductivity versus time curve for each sample. The period when the conductivity value reaches $50 \mu \mathrm{S} / \mathrm{cm}$ is called stability time. This value is the maximum acceptable level of degradation. Rate of dehydrochlorination can be determined by the conductivity of the solution where the evolved $\mathrm{HCl}$ gas is transferred. ${ }^{8}$

Considering the importance of plastic industry, experimental design that is a necessary tool for researchers whose goal is to have a systematic approach for experimentation was used to optimize the processing parameters, such as the amount of stabilizers and temperature for the decomposition of PVC process. A number of types of experimental design are available for different situations. ${ }^{16}$ If more than one factor is under investigation, factorial designs $\left(2^{\mathrm{k}}\right)$ by adding points at the center are used to estimate the important factors and interaction effects. The concept of response surface methodology is used to estimate the pure quadratic and interaction effects. ${ }^{17}$ Among the response surface methods, which are central composite design, boxbehnken design, face centered composite design (FCC), FCC method is used to optimize the processing parameters. ${ }^{18,19}$

The main purpose of this work was to perform statistically designed experiments to investigate the effect of temperature, $\mathrm{ZnSt}_{2}$, and zeolite on thermal stability of PVC.

\section{MATERIALS AND METHODS}

\section{Materials}

PVC powder was provided by Petkim (Petvinil P.38/74). The samples were prepared by mixing PVC powder with different amounts of zinc stearate $\left(\mathrm{ZnSt}_{2}\right)$ and clinoptilolite rich natural zeolite having $45 \mu \mathrm{m}$ average particle size which was supplied from Gördes Region in Western Anatolia. The composition of clinoptilolite rich mineral was 66.36\% $\mathrm{SiO}_{2}, 11.36 \% \quad \mathrm{Al}_{2} \mathrm{O}_{3}, 1.227 \% \quad \mathrm{Fe}_{2} \mathrm{O}_{3}, 3.844 \% \quad \mathrm{~K}_{2} \mathrm{O}$, $0.998 \% \mathrm{Na}_{2} \mathrm{O}, 2.344 \% \mathrm{CaO}, 0.420 \% \mathrm{MgO}, 14.22 \%$ $\mathrm{H}_{2} \mathrm{O}$. The clinoptilolite content was estimated as $80 \%{ }^{20}$ All chemicals were of analytical grade and used as received.

\section{Method}

Different amount of stabilizers were added to $10 \mathrm{~g}$ PVC powder and mixed to form homogeneous blends. Thermal stability test was performed by 763 PVC Thermomat, which was equipped with two heating blocks each with four measuring positions. The reaction vessels that contained $0.5 \mathrm{~g}$. of PVC samples were placed into the heating blocks of PVC Thermomat after they were heated to 140, 150, and $160^{\circ} \mathrm{C}$. During the reaction, $\mathrm{HCl}$ formed was taken up by a nitrogen gas stream and transferred into the measuring vessels. The deionized water absorbed $\mathrm{HCl}$ gas and the change in conductivity of the solution was determined with respect to time by the conductimeter. Therefore, the decomposition process was monitored by measuring the conductivity of aqueous $\mathrm{HCl}$ solution. ${ }^{8,21}$ 
TABLE I

Experimental Factors and Levels Investigated for Thermal Stability of PVC

\begin{tabular}{lcc}
\hline \multicolumn{1}{c}{ Factor } & Low & High \\
\hline ZnSt $_{2}$ & 100 & 400 \\
Zeolite & 100 & 400 \\
Temperature & 140 & 160 \\
\hline
\end{tabular}

\section{Experimental design}

In dehydrochlorination of PVC, induction time, stability time, initial rate constant, and linear region rate constant were chosen as the responses, while the amount of $\mathrm{ZnSt}_{2}$,zeolite, and temperature were considered as factors which were varied over two levels (low and high). The experimental factors and the levels investigated for thermal stability of PVC are given in Table I. The experiments were performed by considering a $2^{3}$ full factorial design with 4 center points, consisting of 20 experiments (two replicates for each experiment). The main purpose of the addition of center point was to provide protection against curvature from the second order effect as well as allow an independent estimate of error to be obtained. Also, FCC design was used to observe the polynomial of higher degree and to compare the results obtained by full factorial design. Both designs were carried out by using Design of Expert 6.0.11.

\section{RESULTS AND DISCUSSION}

\section{Kinetic study of PVC}

The kinetic study was carried out not only to optimize the amount of additives in PVC but also to expose the effect of zinc stearate and zeolite on the stabilization of the polymer at two different temperatures. Figures 1 and 2 indicate the change of conductivity of aqueous solution with respect to time for PVC, PVC stabilized with zinc stearate, and

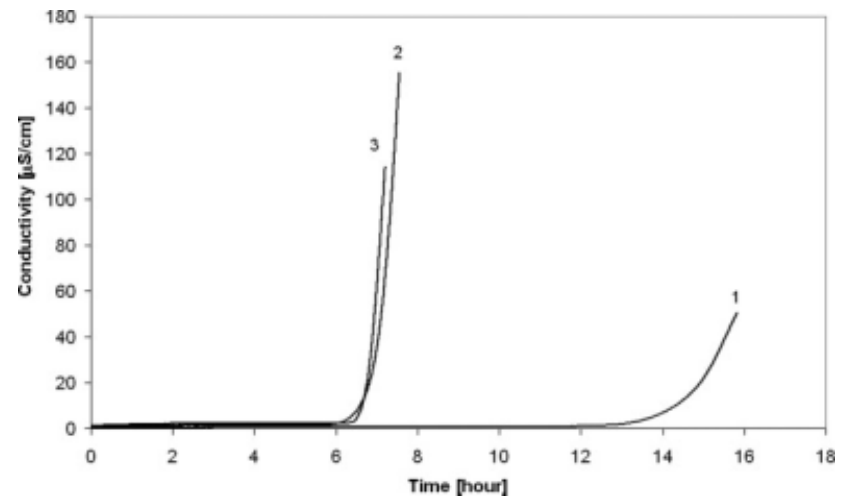

Figure 1 The change of conductivity of aqueous solution with respect to time at $140^{\circ} \mathrm{C}$ for 1-PVC, $2-10 \mathrm{~g}$ PVC stabilized with $400 \mathrm{mg} \mathrm{ZnSt}_{2}$, and 3-10 g PVC stabilized with $400 \mathrm{mg}$ zeolite.

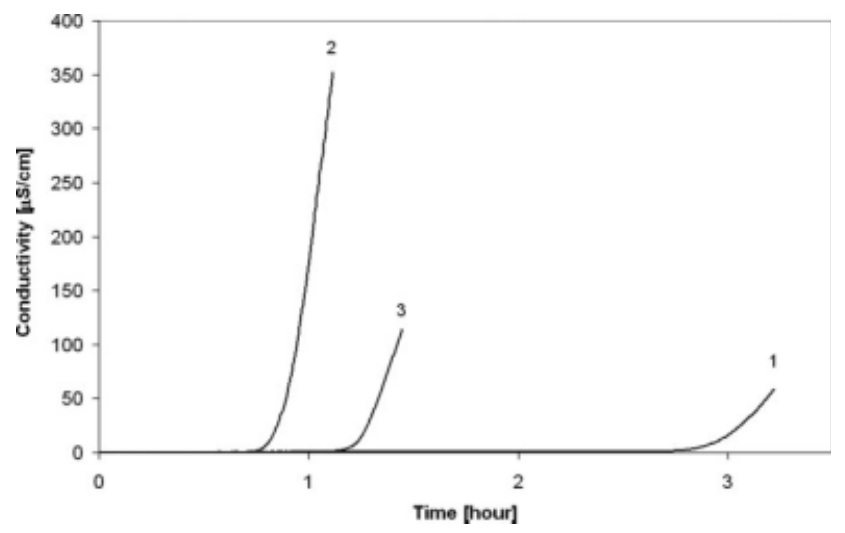

Figure 2 The change of conductivity of aqueous solution with respect to time at $160^{\circ} \mathrm{C}$ for $1-\mathrm{PVC}, 2-10 \mathrm{~g}$ PVC stabilized with $400 \mathrm{mg} \mathrm{ZnSt}_{2}$, and 3-10 g PVC stabilized with $400 \mathrm{mg}$ zeolite.

PVC stabilized with zeolite. By using the curves in these figures, kinetic rate constants of dehydrochlorination reaction were evaluated. The steps used in the calculation of rate constants of degradation reaction were described in the recent studies. ${ }^{8,21}$ In this model, it was assumed that the degradation of PVC was a first order reaction. The rate constant was related to the concentration of $\mathrm{HCl}$ in water $\left(C_{\mathrm{HCl}}\right)$, potential number of double bonds to be formed when $100 \%$ of $\mathrm{HCl}$ was eliminated per $1 \mathrm{~g}$ of PVC $\left(C_{o}\right)$, moles of evolved $\mathrm{HCl}$ gas $\left(n_{\mathrm{HCl}}\right)$, mass of plastigels in reaction vessel $(m)$ :

$$
k=\frac{d C_{\mathrm{HCl}}}{d t} \cdot \frac{1}{C_{o}}=\frac{d n_{\mathrm{HCl}}}{d t} \cdot \frac{1}{m \cdot \mathrm{CF}} \cdot \frac{1}{C_{o}}
$$

where $\mathrm{CF}$ is the correction factor based on the fraction of PVC amount in PVC mixtures. The dehydrochlorination curves indicated in Figures 1 and 2 were separated into two parts, initial region and linear region. Therefore, two rate constants were evaluated for each reaction. Initial rate constants were obtained from the slopes of initial region of the curves where the release of $\mathrm{HCl}$ gas started; whereas linear region rate constants were determined from the slopes of linear region where the release of $\mathrm{HCl}$ gas accelerated. The induction and stability periods of PVC at 140 and $160^{\circ} \mathrm{C}$ are higher than the PVC having additives as this PVC was synthesized by emulsion polymerization. Therefore, it has some organic compounds acting as heat stabilizers such as surface active agents, plasticizer, and anti oxidants, and in literature, it was found that PVC particles are covered by carbon-rich materials, and these additives are $1.6 \%$ of PVC as determined by ethanol extraction. ${ }^{22}$ The obtained induction and stability periods and the calculated rate constants are reported in Table II. The increase in rate constants for PVC stabilized with zinc stearate, in other words, 
TABLE II

Induction, Stabilization Periods, and Rate Constants at 140 and $160^{\circ} \mathrm{C}$ for PVC, $10 \mathrm{~g}$ PVC Stabilized with $400 \mathrm{mg}$ $\mathrm{ZnSt}_{2}$, and $10 \mathrm{~g}$ PVC Stabilized with $400 \mathrm{mg}$ zeolite

\begin{tabular}{|c|c|c|c|c|c|c|c|c|}
\hline \multirow[b]{3}{*}{ Samples } & \multicolumn{8}{|c|}{ Temperature $\left({ }^{\circ} \mathrm{C}\right)$} \\
\hline & \multicolumn{4}{|c|}{140} & \multicolumn{4}{|c|}{160} \\
\hline & $\begin{array}{l}\text { Induction } \\
\text { time }(\mathrm{h})\end{array}$ & $\begin{array}{l}\text { Stability } \\
\text { time }(\mathrm{h})\end{array}$ & $\begin{array}{l}\text { Initial rate } \\
\text { constant } \times \\
10^{6}\left(\min ^{-1}\right)\end{array}$ & $\begin{array}{l}\text { Linear region } \\
\text { rate constant } \\
\times 10^{5}\left(\mathrm{~min}^{-1}\right)\end{array}$ & $\begin{array}{l}\text { Induction } \\
\text { time }(\mathrm{h})\end{array}$ & $\begin{array}{l}\text { Stability } \\
\text { time }(\mathrm{h})\end{array}$ & $\begin{array}{c}\text { Initial rate } \\
\text { constant } \\
\times 10^{6}\left(\mathrm{~min}^{-1}\right)\end{array}$ & $\begin{array}{l}\text { Linear region } \\
\text { rate constant } \\
\times 10^{5}\left(\min ^{-1}\right)\end{array}$ \\
\hline PVC & 15.05 & 15.83 & 2.56 & 0.97 & 2.35 & 3.23 & 4.74 & 4.88 \\
\hline PVC + Zeolite & 6.84 & 6.96 & 2.84 & 6.26 & 1.25 & 1.34 & 17.07 & 13.65 \\
\hline
\end{tabular}

the increasing rate of dehydrochlorination after the consumption of zinc stearate indicated the autoacceleration effect of $\mathrm{HCl}$ and the produced $\mathrm{ZnCl}_{2}$. Unlike zinc stearate, zeolite did not promote dehydrochlorination; therefore, it decreased the rate constants of the sample. The use of zeolite effect in PVC was considered to result from the absorption of $\mathrm{HCl}$ which catalyzed the degradation of PVC. To determine the optimum process parameters for the stabilization of PVC, the conductivity changes of PVC stabilized with different amounts of $\mathrm{ZnSt}_{2}$ and zeolite with respect to time at $140,150,160^{\circ} \mathrm{C}$ are plotted in Figures 3-5. Table III and IV list the kinetic results corresponding to the factorial and face centered composite design. At $140^{\circ} \mathrm{C}$, the sample stabilized with $400 \mathrm{mg}$, ZnSt $\mathrm{Zn}_{2}$ and $400 \mathrm{mg}$, zeolite has the induction value $18.23 \mathrm{~h}$, while the lowest linear region rate constant was obtained for the sample only $100 \mathrm{mg}$, ZnSt ${ }_{2}$ and $100 \mathrm{mg}$, zeolite which meant that small amount of $\mathrm{ZnCl}_{2}$ are released during the dehydrochlorination. The enhancing effect of $\mathrm{ZnSt}_{2}$ on the induction period is verified in Figure 4 as the highest induction time is observed for the sample

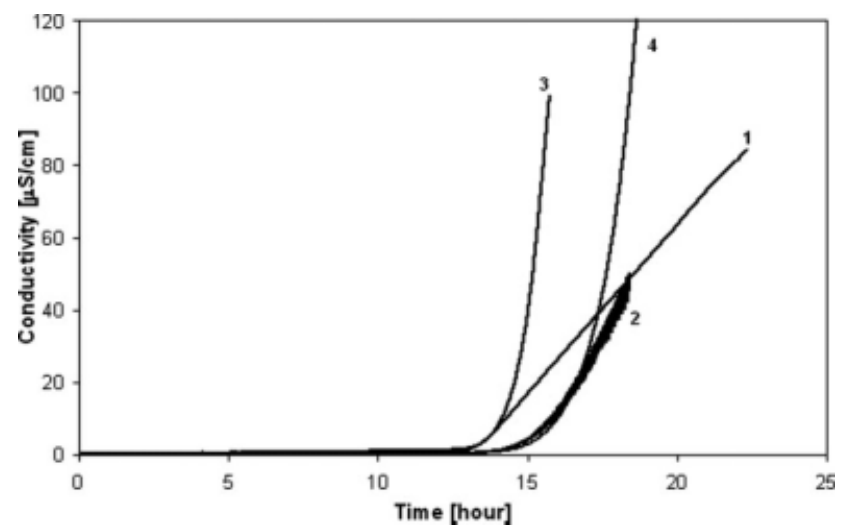

Figure 3 The change of conductivity of aqueous solution with respect to time at $140^{\circ} \mathrm{C}$ for $10 \mathrm{~g}$ PVC stabilized with $\mathrm{ZnSt}_{2}$ and zeolite, 1-PVC having $100 \mathrm{mg} \mathrm{ZnSt}_{2}$ and $100 \mathrm{mg}$ zeolite, 2-PVC having $100 \mathrm{mg} \mathrm{ZnSt}_{2}$ and $400 \mathrm{mg}$ zeolite, 3PVC having $400 \mathrm{mg} \mathrm{ZnSt}{ }_{2}$ and $100 \mathrm{mg}$ zeolite, and 4-PVC having $400 \mathrm{mg} \mathrm{ZnSt}_{2}$ and $400 \mathrm{mg}$ zeolite. having highest amount of $\mathrm{ZnSt}_{2}$. However, PVC stabilized with $100 \mathrm{mg}, \mathrm{ZnSt}_{2}$ and $400 \mathrm{mg}$, zeolite has the lowest linear region rate constant due to the absorption of $\mathrm{HCl}$ evolved at the initial stages of dehydrochlorination by zeolite. At higher temperatures $\left(160^{\circ} \mathrm{C}\right)$, the addition of $400 \mathrm{mg}$ zeolite into PVC not only increase the induction time of PVC but also decrease the linear region rate constant of the sample.

\section{Factorial design for PVC stability}

In factorial design, the interaction between the factors was postulated by the fitted regression model, which can used to obtain the predicted or fitted value of responses. The model representation of this design could be written as:

$$
\begin{aligned}
\hat{y}= & \beta_{o}+\beta_{1} X_{1}+\beta_{2} X_{2}+\beta_{3} X_{3} \\
& +\beta_{12} X_{1} X_{2}+\beta_{13} X_{1} X_{3}+\beta_{23} X_{2} X_{3}
\end{aligned}
$$

where $\hat{y}$ is the response, $\beta_{o}$ is the average value of the experimental responses, $\beta_{1}, \beta_{2}, \beta_{3}$ are the main

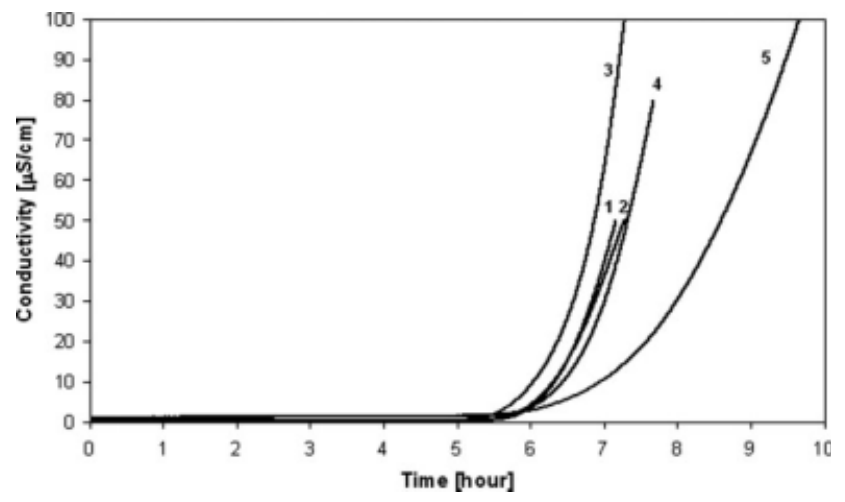

Figure 4 The change of conductivity of aqueous solution with respect to time at $150^{\circ} \mathrm{C}$ for $10 \mathrm{~g}$ PVC stabilized with $\mathrm{ZnSt}_{2}$ and zeolite, 1-PVC having $100 \mathrm{mg} \mathrm{ZnSt}_{2}$ and $250 \mathrm{mg}$

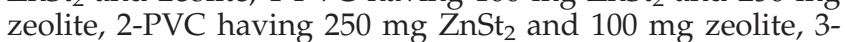
PVC having $250 \mathrm{mg} \mathrm{ZnSt} t_{2}$ and $250 \mathrm{mg}$ zeolite, 4-PVC having $250 \mathrm{mg} \mathrm{ZnSt} 2$ and $400 \mathrm{mg}$ zeolite, and 5-PVC having $400 \mathrm{mg} \mathrm{ZnSt} t_{2}$ and $250 \mathrm{mg}$ zeolite. 


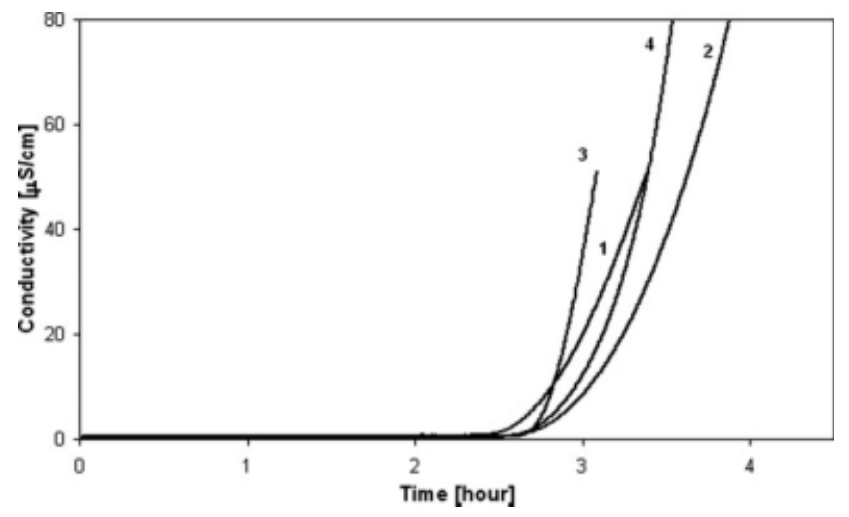

Figure 5 The change of conductivity of aqueous solution with respect to time at $160^{\circ} \mathrm{C}$ for $10 \mathrm{~g}$ PVC stabilized with $\mathrm{ZnSt}_{2}$ and zeolite, 1-PVC having $100 \mathrm{mg} \mathrm{ZnSt}{ }_{2}$ and $100 \mathrm{mg}$

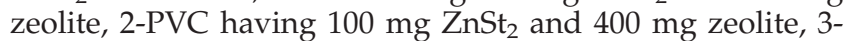
PVC having $400 \mathrm{mg} \mathrm{ZnSt} t_{2}$ and $100 \mathrm{mg}$ zeolite, and 4-PVC having $400 \mathrm{mg} \mathrm{ZnSt}{ }_{2}$ and $400 \mathrm{mg}$ zeolite.

effect coefficients, $\beta_{12}, \beta_{13}, \beta_{23}$ are the interaction coefficients, $X_{1}, X_{2}, X_{3}$ are coded variables that represent the $\mathrm{ZnSt}_{2}$, zeolite, and temperature, respectively.

The fitted regression models for each response are given in eqs. $4-7$. The model results for induction time indicated that zeolite had positive effect, whereas temperature had negative effect on this response. Only temperature had negative effect on the stability time. However, all main and interaction effects are significant on the initial rate constant. Zeolite, temperature and zeolite-temperature effects are considerable on the linear region rate constant.
Induction time

$$
\hat{y}=9.06+0.92 X_{2}-5.9 X_{3}
$$

Stability time

$$
\hat{y}=10.72-7.38 X_{3}
$$

Initial rate constant

$$
\begin{aligned}
\hat{y}= & 7.742 \times 10^{-6}+1.741 \times 10^{-6} X_{1}-3.648 \times 10^{-6} X_{2} \\
& +5.972 \times 10^{-6} X_{3}+1.427 \times 10^{-6} X_{1} X_{3} \\
& +3.501 \times 10^{-6} X_{2} X_{3}
\end{aligned}
$$

Linear region rate constant

$$
\begin{array}{r}
\hat{y}=1.266 \times 10^{-4}+1.025 \times 10^{-4} X_{2}+1.134 \times 10^{-4} X_{3} \\
+9.644 \times 10^{-5} X_{2} X_{3}
\end{array}
$$

However, it is always necessary to examine any interaction that are important as the main effect do not have much meaning when they are involved in significant interaction. Zeolite and temperature; $\mathrm{ZnSt}_{2}$ and temperature effects on initial rate constant and zeolite and temperature effect on linear region rate constant are shown in Figure 6(a,b) respectively. Figure 6(a) indicated that zeolite had not a significant effect at low level of temperature although it had a prominent effect at high level of temperature for both initial rate constant. This result implied that the change in the amount of zeolite in PVC did not

\begin{tabular}{|c|c|c|c|c|c|c|c|c|}
\hline \multirow[b]{2}{*}{ Std } & \multirow{2}{*}{$\begin{array}{l}\text { Run } \\
\text { number }\end{array}$} & \multicolumn{2}{|c|}{$\begin{array}{l}\text { Additive (mg/ } \\
10 \text { g PVC) }\end{array}$} & \multirow{2}{*}{$\begin{array}{c}\text { Temperature } \\
\left({ }^{\circ} \mathrm{C}\right)\end{array}$} & \multirow{2}{*}{$\begin{array}{l}\text { Induction } \\
\text { time }(\mathrm{h})\end{array}$} & \multirow{2}{*}{$\begin{array}{l}\text { Stability } \\
\text { time }(\mathrm{h})\end{array}$} & \multirow{2}{*}{$\begin{array}{c}\text { Initial rate } \\
\text { constant } \times 10^{6}\left(\mathrm{~min}^{-1}\right)\end{array}$} & \multirow{2}{*}{$\begin{array}{c}\text { Linear region rate } \\
\text { constant } \times 10^{5}\left(\mathrm{~min}^{-1}\right)\end{array}$} \\
\hline & & $\mathrm{ZnSt}_{2}$ & Zeolite & & & & & \\
\hline 10 & 1 & 100 & 100 & 160 & 2.57 & 3.38 & 4.68 & 2.46 \\
\hline 16 & 2 & 400 & 400 & 160 & 3.97 & 3.47 & 33.39 & 46.08 \\
\hline 18 & 3 & 250 & 250 & 150 & 7 & 6.87 & 5.42 & 4.34 \\
\hline 12 & 4 & 400 & 100 & 160 & 2.78 & 3.08 & 9.05 & 6.59 \\
\hline 9 & 5 & 100 & 100 & 160 & 2.5 & 3.32 & 4.42 & 2.66 \\
\hline 13 & 6 & 100 & 400 & 160 & 4.37 & 3.62 & 28.29 & 65.88 \\
\hline 11 & 7 & 400 & 100 & 160 & 2.57 & 2.88 & 8.11 & 4.71 \\
\hline 17 & 8 & 250 & 250 & 150 & 6.33 & 7.13 & 2.85 & 2.42 \\
\hline 20 & 9 & 250 & 250 & 150 & 6.25 & 6.99 & 3.27 & 2.25 \\
\hline 7 & 10 & 400 & 400 & 140 & 18.23 & 17.64 & 2.91 & 3.69 \\
\hline 4 & 11 & 400 & 100 & 140 & 15.09 & 15.18 & 2.93 & 2.28 \\
\hline 5 & 12 & 100 & 400 & 140 & 16.04 & 18.43 & 1.12 & 0.48 \\
\hline 6 & 13 & 100 & 400 & 140 & 17.45 & 18.83 & 2.16 & 3.35 \\
\hline 19 & 14 & 250 & 250 & 150 & 7.43 & 7.36 & 4.84 & 3.74 \\
\hline 15 & 15 & 400 & 400 & 160 & 3.85 & 3.39 & 16.98 & 61.44 \\
\hline 1 & 16 & 100 & 100 & 140 & 13.27 & 18.56 & 1.20 & 0.18 \\
\hline 2 & 17 & 100 & 100 & 140 & 13.16 & 18.57 & 1.35 & 0.18 \\
\hline 14 & 18 & 100 & 400 & 160 & 2.66 & 3.61 & 4.79 & 2.19 \\
\hline 3 & 19 & 400 & 100 & 140 & 13.2 & 18.43 & 1.01 & 0.22 \\
\hline
\end{tabular}
significantly effect the degradation behavior of the sample at low temperature. On the other hand, the initial rate constant of degradation reaction increased by increasing the amount of zeolite in PVC at high

TABLE III

Full Factorial Experiment Design $2^{3}$ with 4 Center Point 
TABLE IV

Face Center Composite (FCC) Design

\begin{tabular}{|c|c|c|c|c|c|c|c|c|}
\hline \multirow[b]{2}{*}{ Std } & \multirow{2}{*}{$\begin{array}{l}\text { Run } \\
\text { number }\end{array}$} & \multicolumn{2}{|c|}{$\begin{array}{l}\text { Additive (mg/ } \\
10 \mathrm{~g} \text { PVC) }\end{array}$} & \multirow{2}{*}{$\begin{array}{c}\text { Temperature } \\
\left({ }^{\circ} \mathrm{C}\right)\end{array}$} & \multirow{2}{*}{$\begin{array}{l}\text { Induction } \\
\text { time }(\mathrm{h})\end{array}$} & \multirow{2}{*}{$\begin{array}{l}\text { Stability } \\
\text { time (h) }\end{array}$} & \multirow{2}{*}{$\begin{array}{l}\text { Initial rate constant } \\
\quad \times 10^{6}\left(\mathrm{~min}^{-1}\right)\end{array}$} & \multirow{2}{*}{$\begin{array}{c}\text { Linear region rate } \\
\text { constant } \times 10^{5}\left(\mathrm{~min}^{-1}\right)\end{array}$} \\
\hline & & $\mathrm{ZnSt}_{2}$ & Zeolite & & & & & \\
\hline 19 & 1 & 250 & 250 & 150 & 6.33 & 7.13 & 2.85 & 2.42 \\
\hline 5 & 2 & 100 & 100 & 160 & 2.57 & 3.38 & 4.68 & 2.46 \\
\hline 14 & 3 & 250 & 250 & 160 & 3.25 & 3.18 & 10.90 & 47.90 \\
\hline 9 & 4 & 100 & 250 & 150 & 6.63 & 7.17 & 2.29 & 1.73 \\
\hline 15 & 5 & 250 & 250 & 150 & 7 & 6.87 & 5.42 & 4.34 \\
\hline 7 & 6 & 100 & 400 & 160 & 4.37 & 3.62 & 28.30 & 65.90 \\
\hline 2 & 7 & 400 & 100 & 140 & 15.09 & 15.18 & 2.93 & 2.28 \\
\hline 6 & 8 & 400 & 100 & 160 & 2.78 & 3.08 & 9.05 & 6.59 \\
\hline 12 & 9 & 250 & 400 & 150 & 7.15 & 7.34 & 1.84 & 3.03 \\
\hline 18 & 10 & 250 & 250 & 150 & 6.25 & 6.99 & 3.27 & 2.25 \\
\hline 10 & 11 & 400 & 250 & 150 & 7.64 & 8.62 & 4.92 & 2.27 \\
\hline 20 & 12 & 250 & 250 & 150 & 7.43 & 7.36 & 4.84 & 3.74 \\
\hline 13 & 13 & 250 & 250 & 140 & 17.47 & 17.25 & 1.07 & 0.96 \\
\hline 17 & 14 & 250 & 250 & 150 & 6.29 & 7.11 & 2.83 & 2.40 \\
\hline 8 & 15 & 400 & 400 & 160 & 3.97 & 3.47 & 33.40 & 46.10 \\
\hline 1 & 16 & 100 & 100 & 140 & 13.27 & 18.56 & 1.20 & 0.19 \\
\hline 11 & 17 & 250 & 100 & 150 & 6.53 & 7.28 & 0.79 & 1.84 \\
\hline 4 & 18 & 400 & 400 & 140 & 18.23 & 17.64 & 2.91 & 3.69 \\
\hline 3 & 19 & 100 & 400 & 140 & 16.04 & 18.43 & 1.12 & 0.48 \\
\hline
\end{tabular}

temperature. Same degradation behavior was observed for the sample stabilized with zinc stearate at 140 and $160^{\circ} \mathrm{C}$. Linear region rate constant was increased when PVC stabilized with $400 \mathrm{mg}$ zeolite at high level of temperature as displayed in Figure 6(b).

The response surface and contour plots for all responses are given in Figures 7-10. Figures 7 and 8 demonstrated that the response surface plots were plane, and the contour plots contained parallel straight lines. The result plots confirmed with the fitted regression model, which was explained only by the main effect instead of interaction. In that cases, the induction and stability results were well modeled by first order model.

Figures 9 and 10 show the response surface and contour plots of initial and linear region rate constants, respectively. In these figures, the significant interaction effects twisted the plane resulting curved contour lines. Thus, interaction was a form of curvature in the underlying response surface model for these responses. Initial and linear region rate constants were modeled by second order model. Temperature-zeolite and temperature- $\mathrm{ZnSt}_{2}$ contributed curvature effect on initial rate constant, whereas temperature-zeolite gave the curvature effect on linear region rate constant with the higher regression coefficient.

The optimum conditions for dehydrochlorination of PVC were determined as $163.06 \mathrm{mg} \mathrm{ZnSt} 2,399.99$ $\mathrm{mg}$ zeolite, and $140^{\circ} \mathrm{C}$ with a desirability of 0.932 .
Face centered composite (FCC) design for PVC stability

FCC model was fitted by the polynomial of higher degree which could be shown as;

$$
\begin{aligned}
\hat{y}= & \beta_{0}+\beta_{1} x_{1}+\beta_{2} x_{2}+\beta_{3} x_{3}+\beta_{12} x_{1} x_{2}+\beta_{13} x_{1} x_{3} \\
& +\beta_{23} x_{2} x_{3}+\beta_{11} x_{1}^{2}+\beta_{22} x_{2}^{2}+\beta_{33} x_{3}^{2}
\end{aligned}
$$

where $\hat{y}$ is the response, $\beta_{o}$ is the average value of the experimental responses, $\beta_{1}, \beta_{2}, \beta_{3}$ are the main effect coefficients, $\beta_{12}, \beta_{13}, \beta_{23}$ are the interaction coefficients, $\beta_{11}, \beta_{22}, \beta_{33}$ are the coefficients of pure quadratic terms, $X_{1}, X_{2}, X_{3}$ are coded variables that represent the $\mathrm{ZnSt}_{2}$, zeolite, and temperature, respectively.

The fitted regression models for each response are given in eqs. 9-12. These equations revealed that the main, interaction, and pure quadratic terms were significant for all responses.

Induction time

$$
\begin{aligned}
\hat{y}= & 6.83+0.48 X_{1}+0.95 X_{2}-6.32 X_{3}-0.044 X_{1}^{2} \\
& -0.34 X_{2}^{2}+3.18 X_{3}^{2}-0.03 X_{1} X_{2}-0.52 X_{1} X_{3} \\
& -0.37 X_{2} X_{3}
\end{aligned}
$$

Stability time

$$
\begin{aligned}
& \hat{y}=7.21-0.32 X_{1}+0.30 X_{2}-7.03 X_{3}+0.51 X_{1}^{2}- \\
& 0.077 X_{2}^{2}+2.83 X_{3}^{2}+0.34 X_{1} X_{2}+0.46 X_{1} X_{3}-0.21 X_{2} X_{3}
\end{aligned}
$$




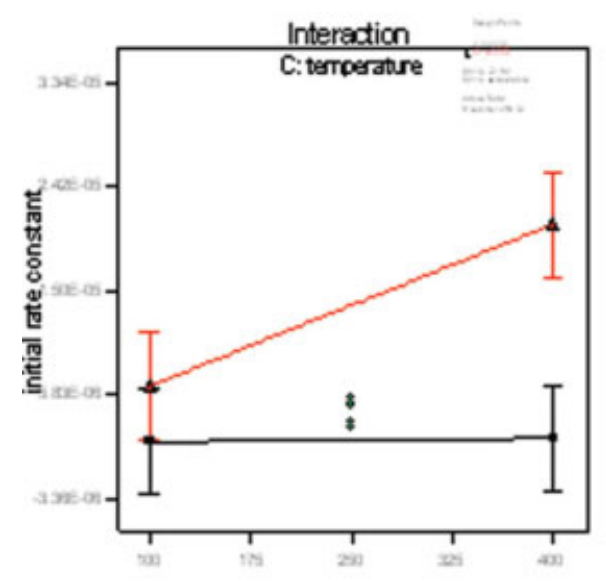

B: aedite

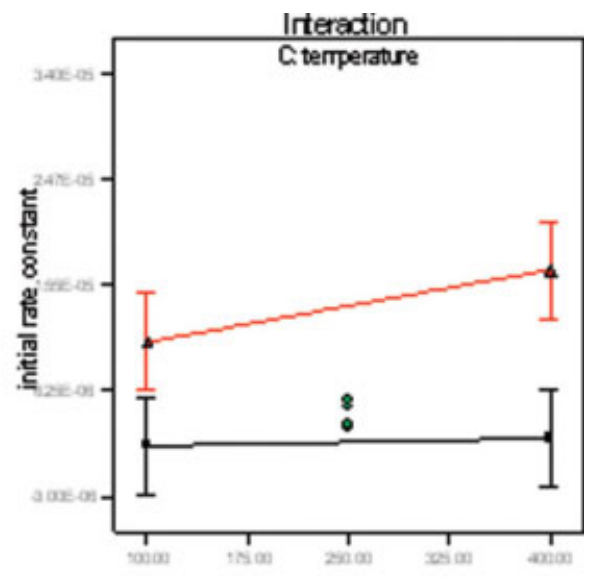

A历 $\Re 2$

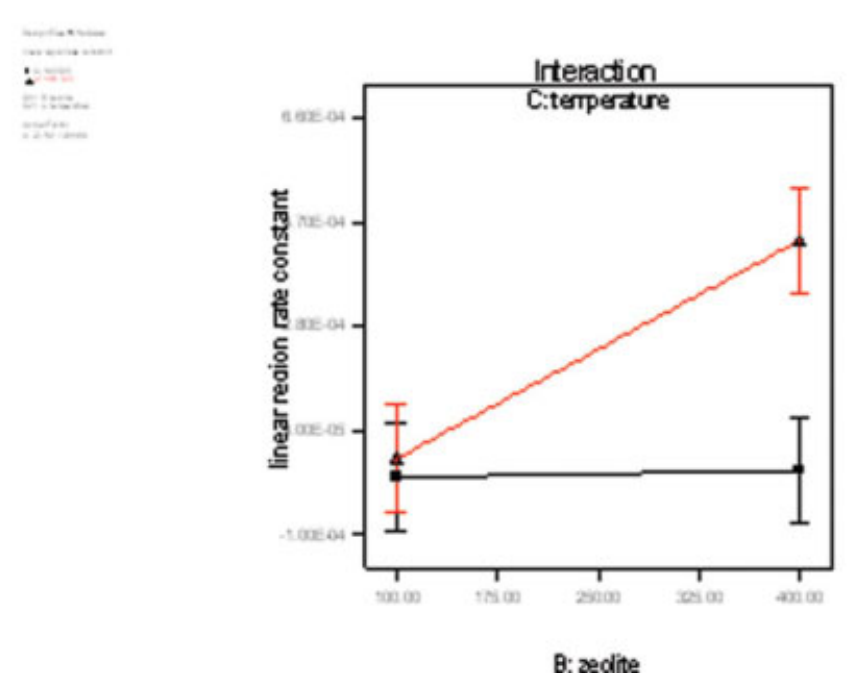

Figure 6 Interaction effect plot for (a) initial rate constant and (b) linear region rate constant. [Color figure can be viewed in the online issue, which is available at www.interscience.wiley.com.]
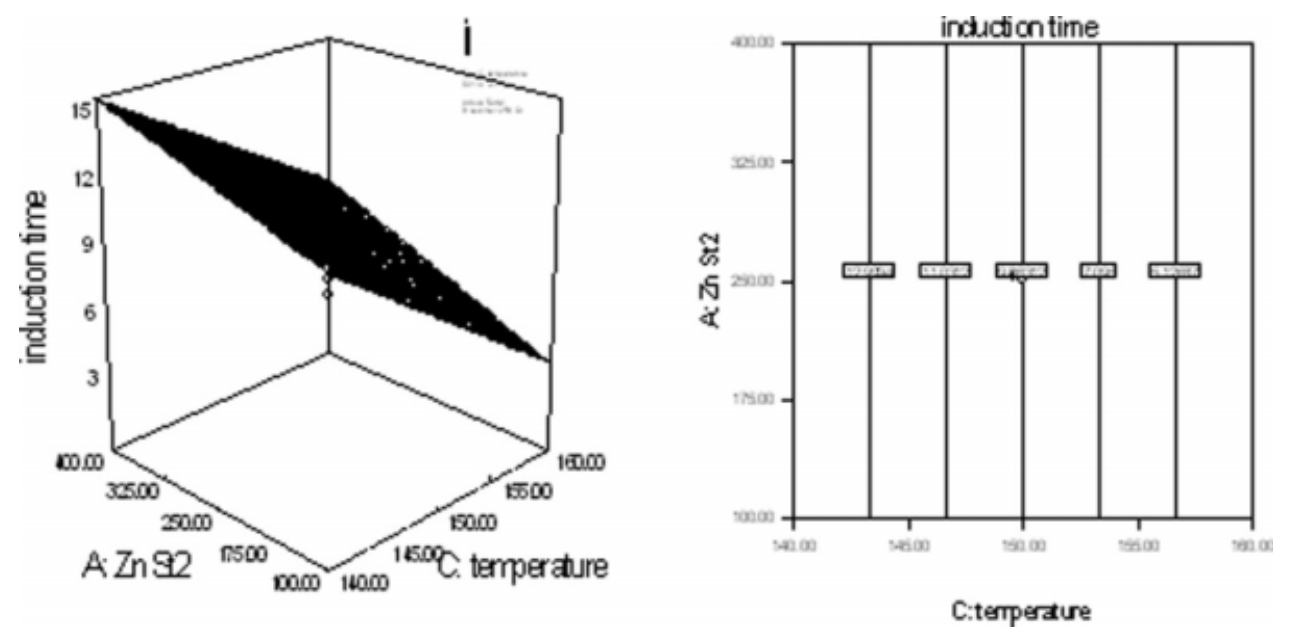

Figure 7 Response surface and contour plot of induction time. 

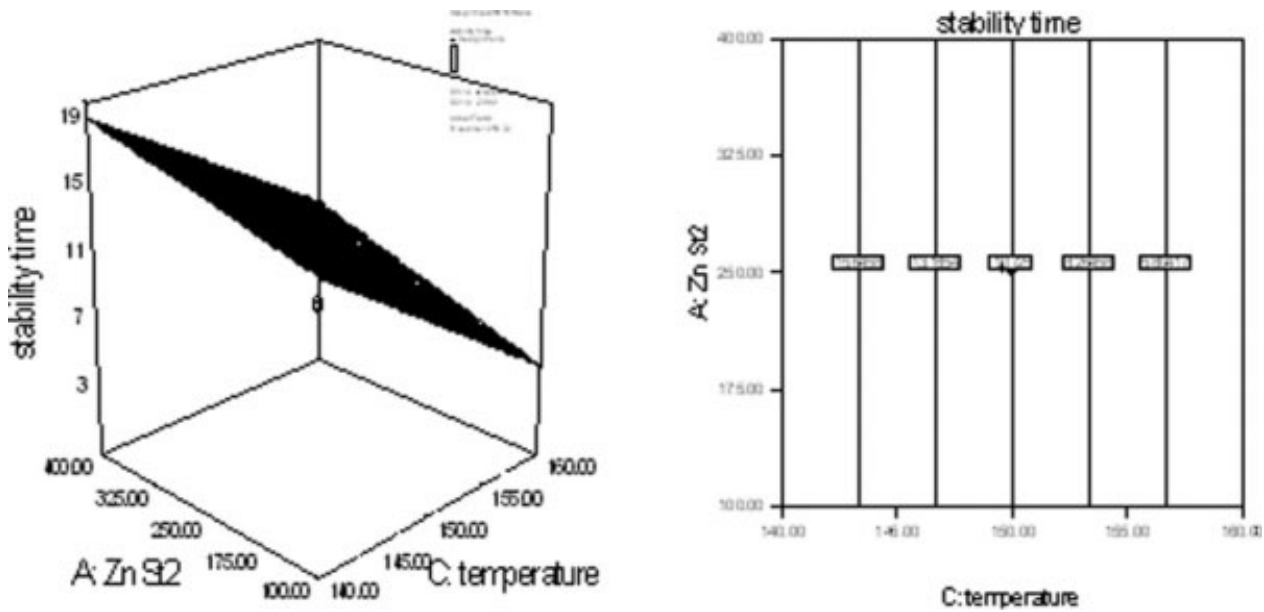

Figure 8 Response surface and contour plot of stability time.

Initial rate constant

$$
\begin{aligned}
\hat{y} & =2.699 \times 10^{-6}+1.562 \times 10^{-6} X_{1}+4.892 \times 10^{-6} X_{2} \\
& +7.705 \times 10^{-6} X_{3}+2.434 \times 10^{-6} X_{1}^{2}+1.422 \times 10^{-7} X_{2}^{2} \\
& +4.792 \times 10^{-6} X_{3}^{2}+9.875 \times 10^{-8} X_{1} X_{2}+7.437 \\
& \times 10^{-7} X_{1} X_{3}+6.009 \times 10^{-6} X_{2} X_{3}
\end{aligned}
$$

Linear region rate constant

$$
\begin{aligned}
\hat{y} & =3.939 \times 10^{-5}-9.829 \times 10^{-6} X_{1}+1.058 \times 10^{-4} X_{2} \\
& +1.614 \times 10^{-4} X_{3}-3.484 \times 10^{-5} X_{1}^{2}-3.051 \times 10^{-5} X_{2}^{2} \\
& +1.894 \times 10^{-4} X_{3}^{2}-2.852 \times 10^{-5} X_{1} X_{2}-2.621 \\
& \times 10^{-5} X_{1} X_{3}+1.266 \times 10^{-4} X_{2} X_{3}
\end{aligned}
$$

The main and interaction effect plots for each response are shown in Figures 11 and 12, respectively. For induction time, $\mathrm{ZnSt}_{2}$ had a linear positive effect, whereas for initial rate constant it pointed out positive curvature effect. On the other hand,
$\mathrm{ZnSt}_{2}$ showed negative curvature effect for stability time and linear region rate constant. Zeolite indicated linear positive effect for stability time and initial rate constant, although it had positive curvature effect on responses, induction time and linear region rate constant. Moreover, temperature demonstrated negative curvature effect on induction and stability periods, but reverse behavior was observed for the initial and linear region rate constant.

At low level of temperature, $\mathrm{ZnSt}_{2}$ positively affected the induction time, whereas at high level of temperature, it had no significant effect on induction time as shown in Figure 12(a). Varying the amount of zeolite affected the induction time at low level of temperature as indicated in Figure 12(a). The effect of zeolite and zinc stearate on induction time could be assumed negligible when compared to the other interaction parameters. However, increasing the temperature pointed out the curvature effect on this response due to its high pure quadratic interaction
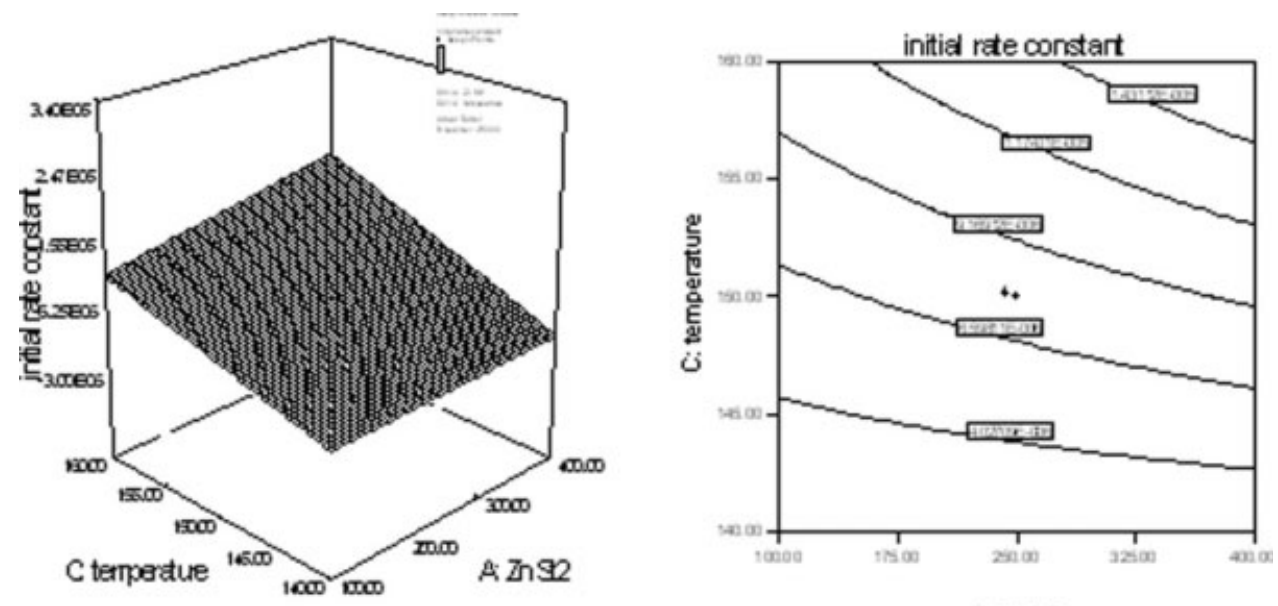

$A \square \cap 2$

Figure 9 Response surface and contour plot of initial rate constant. 

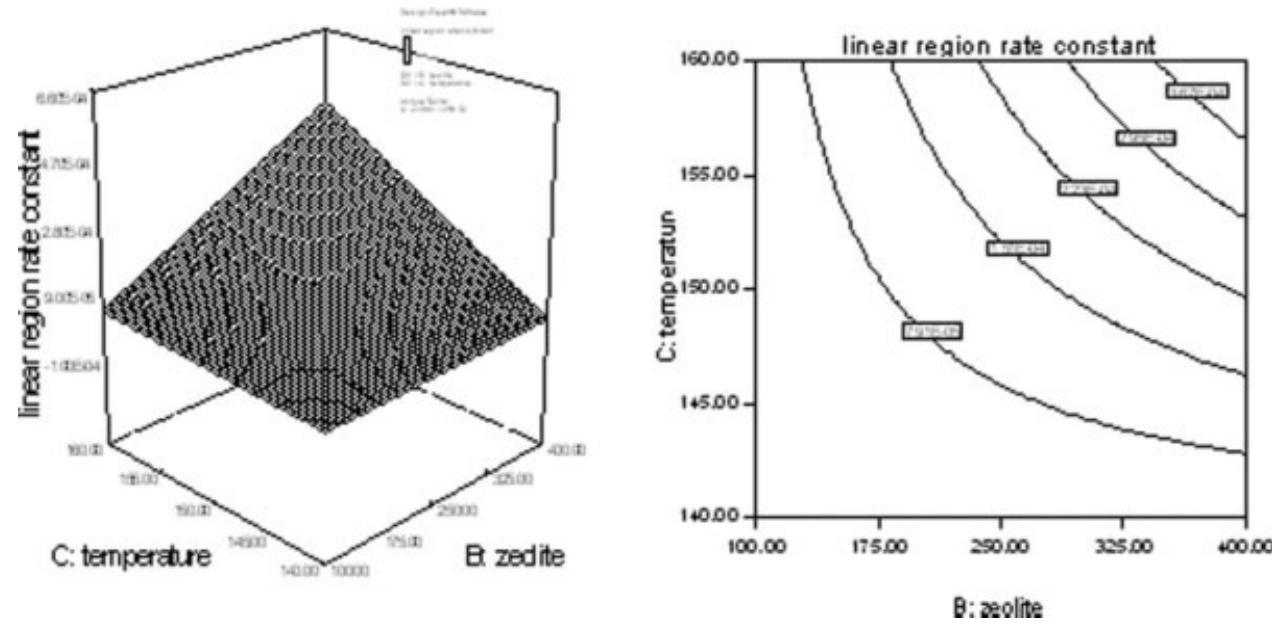

Figure 10 Response surface and contour plot of linear region rate constant.
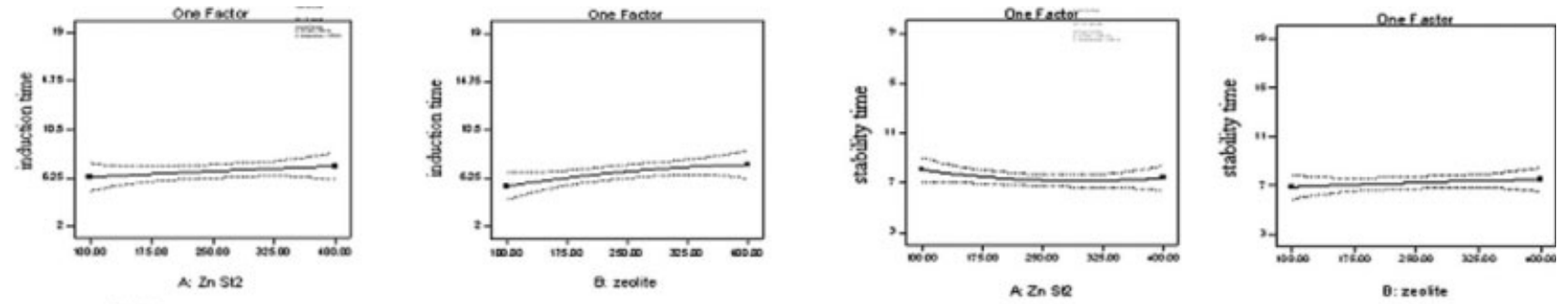

$\overline{=}$

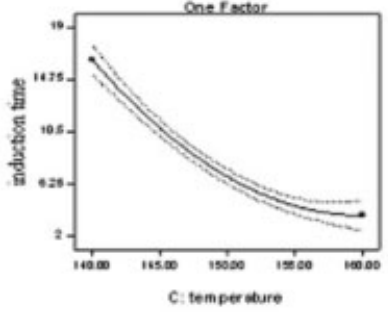

(a)
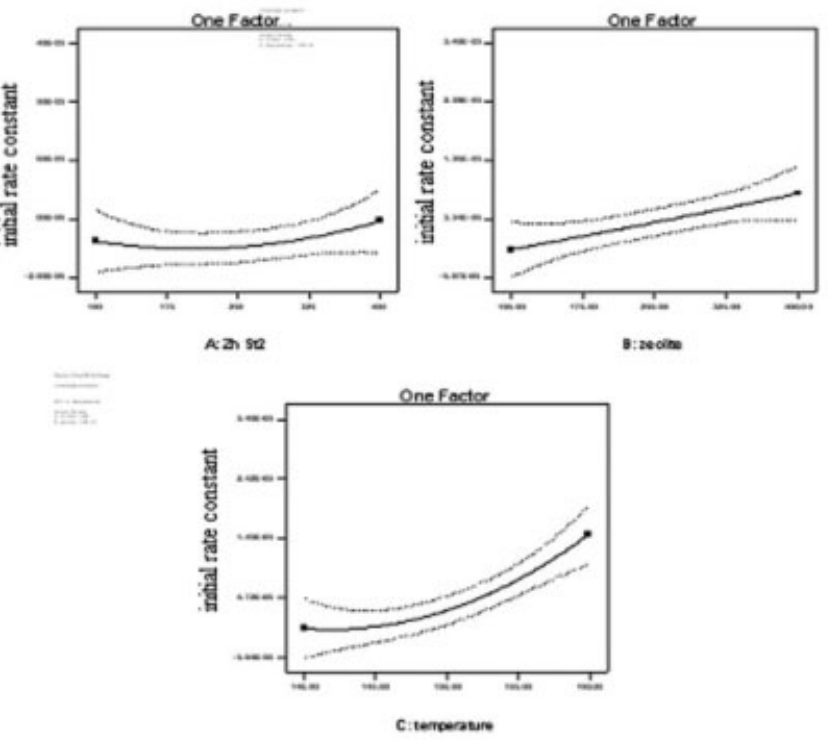

(c)

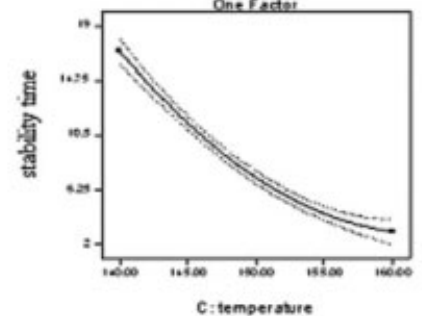

(b)
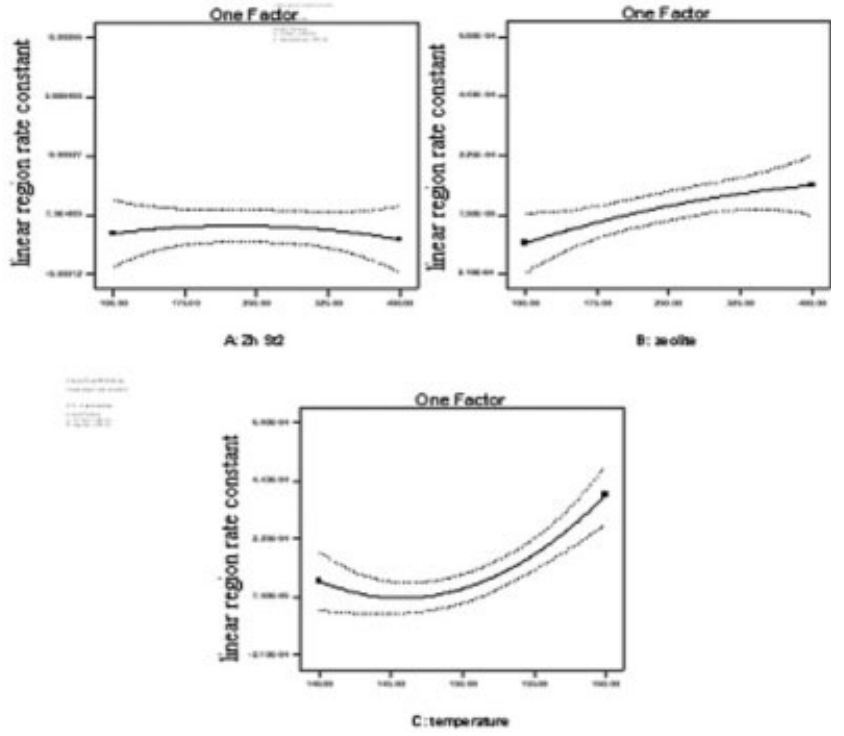

(d)

Figure 11 Main effect plot for (a) induction time, (b) stability time, (c) initial rate constant, and (d) linear region rate constant. 

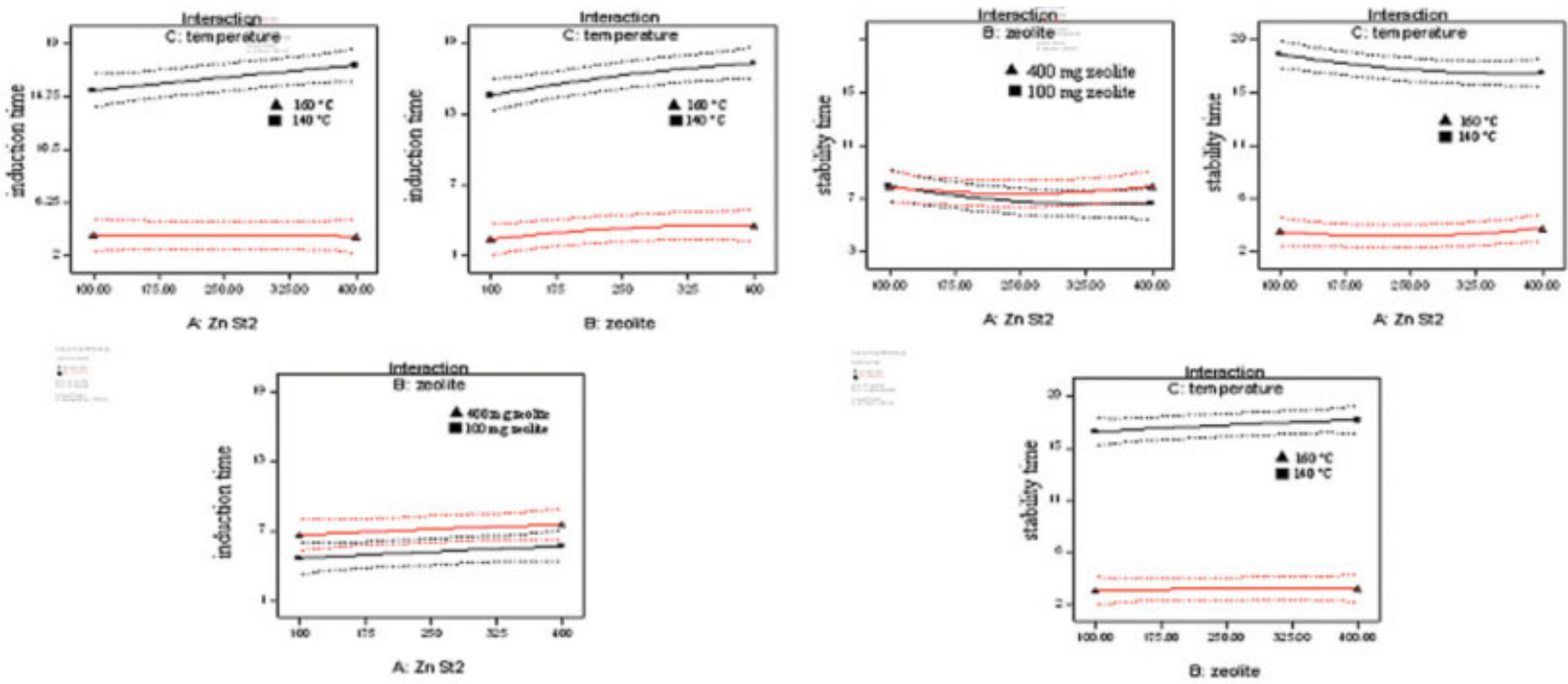

(a)

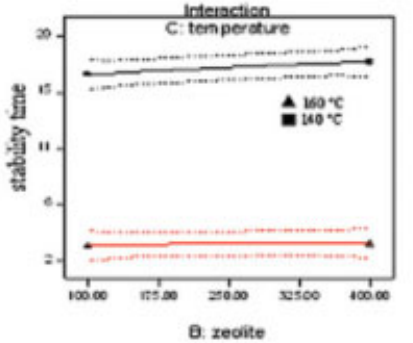

(b)
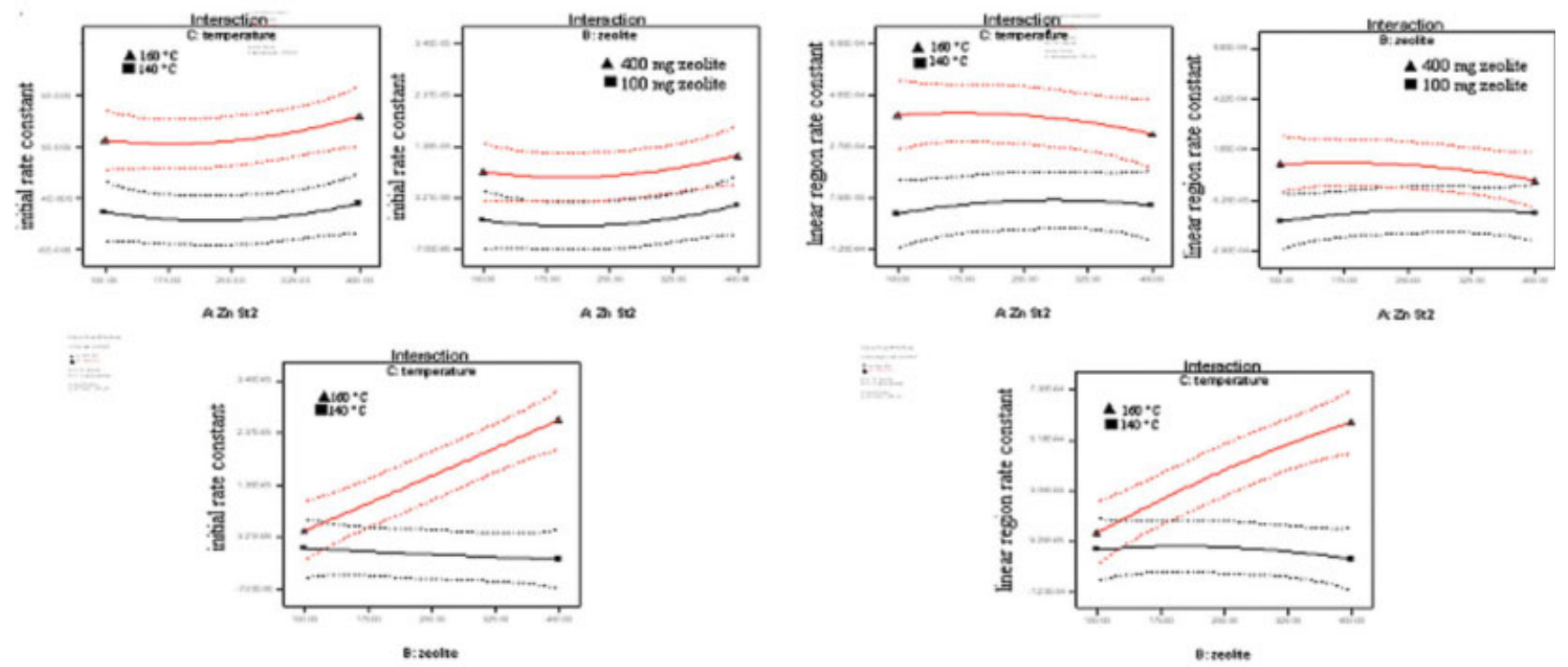

(c)

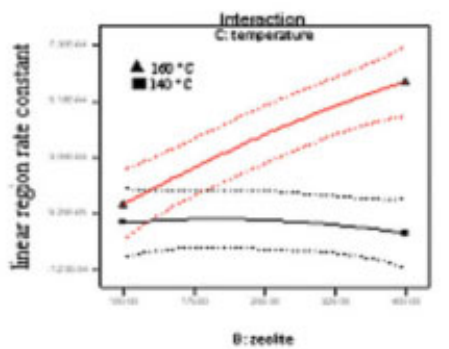

(d)

Figure 12 Interaction effect plot for (a) induction time, (b) stability time, (c) initial rate constant, and (d) linear region rate constant. [Color figure can be viewed in the online issue, which is available at www.interscience.wiley.com.]

value as shown in eq. 9. In Figure 12(b), there was significant interaction between zeolite and $\mathrm{ZnSt}_{2}$ on stability time because of the intersection of the interaction lines. Therefore, it was found that the use of zeolite and zinc stearate in PVC increased the stability time of the sample. The stability time was not affected by the increasing the amount of zeolite at two different temperatures, whereas stability period of the sample decreased when $400 \mathrm{mg}$. zeolite was used at $140^{\circ} \mathrm{C}$. This result confirmed the autoacceleration effect of $\mathrm{ZnCl}_{2}$ which was produced by consuming zinc stearate during the degradation of PVC. Figure 12(c), represents the interaction effects on ini- tial region rate constant. Both at low and high levels of zeolite and temperature, the addition of $\mathrm{ZnSt}_{2}$ increased the initial rate constant, showing a curvature effect. Although the addition of zeolite had negative effect on initial rate constant at low level of temperature, it showed positive effect on the same response at high level of temperature. This result revealed that the use of high level of zeolite in PVC decreased the degradation of the polymer. As shown in Figure 12(d), at low level of zeolite and temperature, the addition of $\mathrm{ZnSt}_{2}$ increased the linear region rate constant, whereas at high level of zeolite and temperature, this response showed a negative 

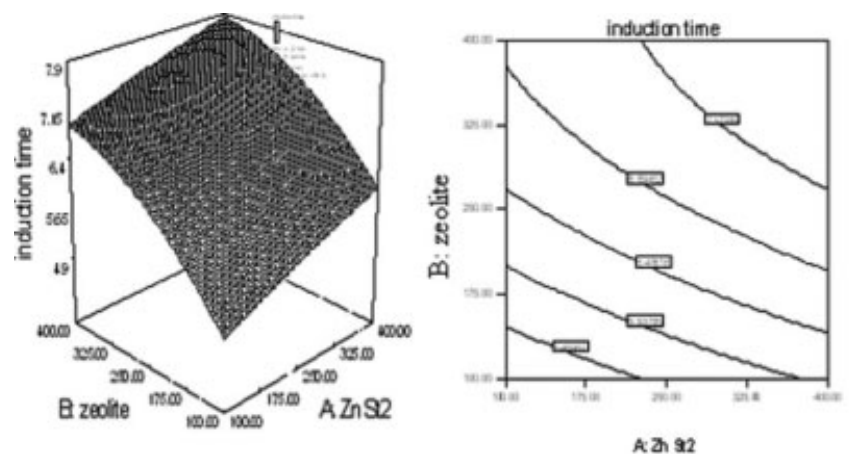

(a)
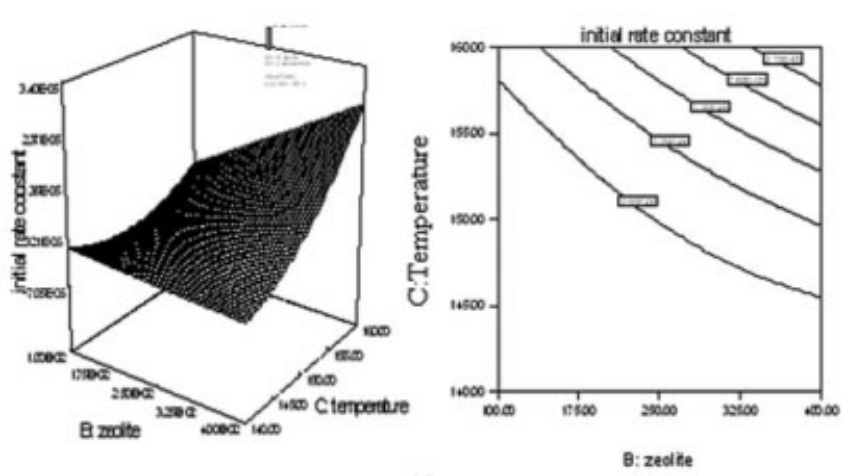

(c)
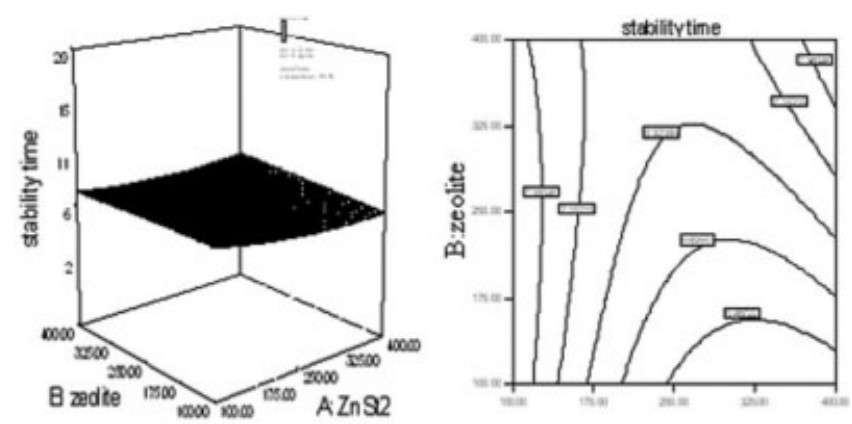

(b)
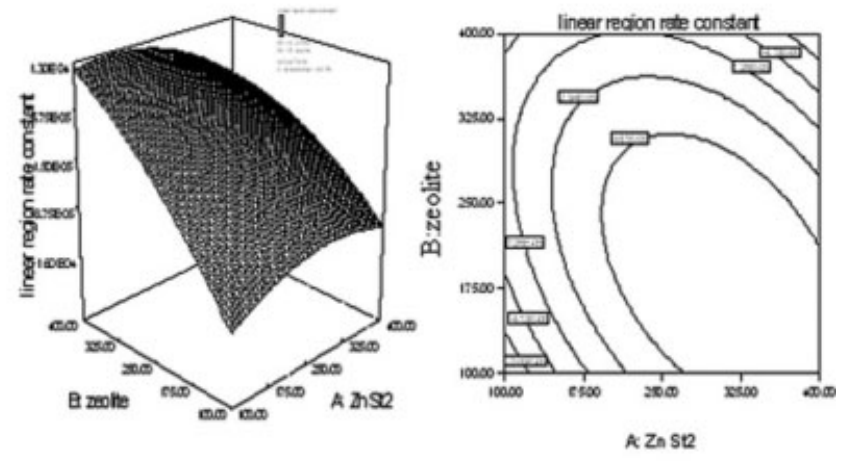

(d)

Figure 13 The response surface and counter plots for (a) induction time, (b) stability time, (c) initial rate constant, and (d) linear region rate constant.

effect by increasing $\mathrm{ZnSt}_{2}$ amount indicating curvature behavior. By increasing zeolite amount, linear region rate constant slightly decreases at low level of temperature, whereas it showed positive effect on the same response at high level of temperature.

Figure 13 shows the response surface and contour plots for all responses. Twisted planes were obtained due to their pure quadratic and interaction effects for the responses resulting in curved contour lines. Among all the responses, linear region rate constant implied the most significant curvature effect with higher pure quadratic interaction coefficient.

The optimum conditions for dehydrochlorination of PVC were determined as $400 \mathrm{mg} \mathrm{ZnSt}{ }_{2}, 333.24$ $\mathrm{mg}$ zeolite, and $140^{\circ} \mathrm{C}$ with a desirability of 0.956 which was higher than the desirability obtained by factorial design.

\section{CONCLUSIONS}

Two factorial and FCC designs were used to investigate the dehydrochlorination of PVC with four responses (induction time, stability time, initial rate constant, and linear region rate constant) and three factors ( $\mathrm{ZnSt}_{2}$, zeolite, temperature).

The regression model representation of the experiment was fitted to the first order model including the main and interaction effect of the responses. The results of main effects revealed that the temperature had a positive effect on initial and linear region rate constants, although it had a negative effect on other responses. $\mathrm{ZnSt}_{2}$ only attributed towards to the initial rate constant. Zeolite had a positive effect on all responses except stability time. The stabilizing effect of zeolite on the other responses was deliberated the results from the absorption of $\mathrm{HCl}$ which was thought to reduce the autocatalytic effect of this gas evolved at initial stage of the dehydrochlorination. The interaction effects should have been considered regardless the main effect, as the main effects did not have much contribution in the presence of significant interaction. Zeolite-temperature interaction indicated that there was no significant effect on the initial and linear region rate constant at low level, whereas a positive effect was observed on these responses at high level. $\mathrm{ZnSt}_{2}$-temperature interaction was effective only for initial rate constant at high level of temperature indicating the power of $\mathrm{ZnSt}_{2}$ to inhibit the dehydrochlorination but as soon as this was finished $\mathrm{HCl}$ gas evolved instantaneously. The fitted model was described by first order pattern for induction and stability time because of the fact that the response surface and contour plots were composed of parallel straight lines. As the shape of these plots gave a clue which parameters were significant, it can be concluded that the model 
was well explained only by main effects for these responses. In other responses (initial and linear region rate constant), the significant interaction effects, which was a form of curvature in the underlying response surface model, twisted the plane resulting curved contour lines. Hence, these responses were modeled by second order model.

FCC model including the main, interaction, and pure quadratic term stated that the second order model was an appropriate approximation. In the main effects plots, $\mathrm{ZnSt}_{2}$ had a linear and curvature positive effect on induction time and initial rate constant, whereas it had a negative curvature effect on stability time and linear region rate constant. Zeolite had positive effect on all responses, linear for stability time and initial rate constant and curvature for induction time and linear region rate constant. Temperature had a negative curvature effect on induction and stability time, whereas it had a positive curvature effect on initial and linear region rate constants. At low level of temperature, $\mathrm{ZnSt}_{2}$ positively affected the induction time. Increasing the amount of zeolite indicated the curvature effect on induction time due to its high pure quadratic interaction value. There was significant interaction between zeolite and $\mathrm{ZnSt}_{2}$, whereas $\mathrm{ZnSt}_{2}$ and temperature effect implied a curvature behavior on stability time. Both at low and high levels of zeolite and temperature, the addition of $\mathrm{ZnSt}_{2}$ increased the initial rate constant, showing a curvature effect. It was observed that the addition of zeolite had negative effect on initial rate constant at low level of temperature while, it showed positive effect on the same response at high level of temperature. The results implied that at low level of zeolite and temperature, the addition of $\mathrm{ZnSt}_{2}$ increased the linear region rate constant, whereas at high level this response showed a negative effect by increasing $\mathrm{ZnSt}_{2}$ amount indicating curvature behavior. Response surface and contour plots imparted that pure quadratic and interaction effects were dominant in all responses. Contour lines were curved resulting the plane to twist. The high polynomial order model was fitted for FCC model.

The optimum process parameters for factorial and FCC designs were determined as $163.06 \mathrm{mg} \mathrm{ZnSt}_{2}$, $399.99 \mathrm{mg}$ zeolite, and $140^{\circ} \mathrm{C}$ and $400 \mathrm{mg} \mathrm{ZnSt}{ }_{2}$,
$333.24 \mathrm{mg}$ zeolite and $140^{\circ} \mathrm{C}$, respectively. The evaluated values were confirmed by PVC Thermomat after the design had been completed. All the results pointed out that FCC design was superior to factorial design because of its pure quadratic effects contribution and its higher overall desirability for thermal stability of PVC.

The authors thank Assoc. Prof. Figen Tokatlı for her great support and suggestions.

\section{References}

1. Àvila, A.; Sánchez, E. I.; Gutiérrez, M. I. Chemom Intell Lab Syst 2005, 77, 247.

2. Santamaria, E.; Edge, M. J Appl Polym Sci 2004, 93, 2744.

3. Yoshioka, T.; Kameda, T.; Leshige, M.; Okuwaki, A. Polym Degrad Stab 2008, 93, 1822.

4. Frye, A. H.; Horst, R.W. J Polym Sci 1959, 40, 419.

5. Weschler, C. J. Atmos Environ 2009, 43, 153.

6. Liu, Y. B.; Liu, W. Q.; Hou, M. H. Polym Degrad Stab 2007, 92, 1565.

7. Benavides, R.; Castillo, B. M.; Castaneda, A. O.; López, G. M.; Arias, G. Polym Degrad Stab 2001, 73, 417.

8. Atakul, S.; Balköse, D.; Ülkü, S. J Vinyl Addit Technol 2005, $11,47$.

9. Egbuchunam, T. O.; Balköse, D.; Okieimen, F. E. Polym Degrad Stab 2007, 92, 1572.

10. Titow, W. V.; PVC Technology; Applied Science Publishers: London and New York, 1985.

11. Zhong, B. Y.; Ming, H. Z.; Xing, L. S.; Xue, W. Z. Polym Degrad Stab 2008, 93, 448.

12. Van der Ven, L.; Van Gemert, M. L. M.; Batenburg, L. F.; Keern, J. J.; Gielgens, L. H.; Koster, T. P. M. Appl Clay Sci 2000, 17, 25.

13. Göktaş, S.; Ülkü, S.; Bayraktar, O. Appl Clay Sci 2008, 40, 6.

14. Fillippidis, A.; Kantiranis, N. Desalin 2007, 213, 47.

15. Demir, H.; Sipahioğlu, M.; Balköse, D.; Ülkü, S. J Mater Process Technol 2008, 195, 144.

16. Montgomery, D. Design and Analysis of Experiment; Wiley: NewYork, 2001.

17. Lundstedt, T.; Seifert, E.; Abramo, L.; Thelin, B.; Nayström, A.; Pettersen, J.; Bergman, R. Chemom Intell Lab Syst 1998, 42,3 .

18. Chen, C. H.; Lo, Y. W. J Appl Polym Chem 1999, 73, 2755.

19. Goupy, J. Chemom Intell Lab Syst 2006, 80, 156.

20. Top, A.; Ülkü, S. Appl Clay Sci 2004, 27, 13.

21. Erdoğdu, C. A.; Atakul, S.; Balköse, D.; Ülkü, S. Chem Eng Comm 2009, 196, 148.

22. Savrık, S. A.; Yılmaz, M. C.; Potur, F.; Balköse, D.; Ulutan, S.; Ülkü, S. In 32nd International Conference on Vacuum Microbalance and Thermoanalytical Techniques proceeding Book, Lublin, Poland, 2009, p 19. 